\title{
Economic Burden of Unintended Pregnancies from Societal Perspective: A Case of Nepal
}

\author{
Mr. Vishnu Prasad Sapkota ${ }^{1}$, Mr. Liladhar Dhakal', \\ Dr. Shiva Raj Adhikari ${ }^{3}$
}

\begin{abstract}
Introduction: Unintended pregnancy includes unwanted and mistimed pregnancy. Nepal has high proportion of unintended pregnancies. An unintended pregnancy has cost implication through different medical conditions to individual, service provider and society. However, till date there is no information about how much cost does the unintended pregnancy incur to the society in Nepal. The objective of this study is to estimate the national annual economic burden of unintended pregnancies in Nepal.
\end{abstract}

Methods: This study adopted societal perspective to identify, measure and value the resources required to manage pregnancy outcomes. The costs include direct medical costs, direct nonmedical costs and indirect costs. We collected data for this study from 27 hospitals and 121 maternal service clients. Transition probabilities were taken from several secondary sources. Total annual burden of unintended pregnancy was estimated by a Markov model using the cohort simulation approach. The input parameters in the model were costs and likelihood of occurrence of the given pregnancy outcome.

Findings: Total annual burden of unintended pregnancies was estimated to be 2649.558 and 12330.59 NPR from provider and societal perspective. The greatest share of the burden was borne by delivery services followed by management of maternal and ANC check-ups. The total burden is most sensitive to cost of normal delivery, CS and ANC services.

Conclusion: Majority of unintended pregnancies undergo full term pregnancy incurring huge economic burden to the society. National Annual economic burden was estimated to be around 2649.558 and 12330.59 NPR from provider and societal perspective. Programs reducing unintended pregnancies will provide economic benefit to the society.

Keywords: Unintended Pregnancies, Societal Perspective, Economic Burden, Cost of Illness

$1 \mathrm{Mr}$. Sapkota is associated to Institute for Nepal Environment and Health System Development, Shantinagar, Newbaneshwor, Kathmandu Nepal.

2 Mr. Dhakal is associated to Nepal Development Society, Chitwan Nepal

3 Dr. Adhikari is associate professor of economics at Patan Multiple Campus, Tribhuvan University, Lalitpur, Nepal 


\section{INTRODUCTION}

Unintended pregnancies usually include unwanted and mistimed pregnancies. Pregnancies that occur when no children or no more children were desire are unwanted, and pregnancies that occur earlier than desired are mistimed (John et al., 2003). Developing countries have high proportion of such pregnancies (Jessica \& Michael, 2008) despite the fact that contraceptive methods are available free of cost from all public health facilities, and on purchase in private health facilities. In Nepal, latest national level Demographic and Health Survey estimated more than one in four pregnancies as unintended (MOHP, et al., 2012) . The negative impacts of such pregnancies on health of mother, child and family have been well documented (Adam et al, 2011). Such adverse effects also imposes economic burden on women, children, and households as well as on healthcare systems. A study based on a review of published papers reported that financial, social and physical cost of unintended pregnancy is higher in developing countries compared to developed countries (Jessica, et al, 2008).

Unintended pregnancies impose burden on the individuals and society through various adverse pregnancy outcomes. Unintended pregnancy has negative effect on timing of antenatal care, breastfeeding, nutritional status, vaccination, birth weight and mortality of children (Jessica et al., 2008). Risk of abortion, smoking, delayed antenatal care, pre-term and low birth weight baby is higher among women who have unintended pregnancy compared to those having intended pregnancy (Kubička, et al., 1995; Pulley, et al., 2002). Studies from Nepal and India reported that unintended pregnancy has negative impact on the vaccination, nutritional status and survival of the unintended baby (Singh, et al. , 2013; Singh, et al., 2012). Couple having unintended pregnancy has more mental health problems, and it costs to the service providers in terms of counseling and treatment (Puri, 2006).These evidences show that health care needs for an unintended pregnancy are broader and more costly than health care need of the intended pregnancy. However, only a few countries have attempted to estimate the economic burden of unintended pregnancies. In Norway, the burden amounts to 164 million Norwegian Kroner (Henry, et al., 2015), 293 million euro in Spain(Lete, et al., 2015), and 4.099 billion Brazilian dollar in Brazil (Le et al., 2014). Studies conducted in high and middle income countries documented a high cost saving for health services and public service by the prevention of unintended pregnancies (Henry, et al., 2015; Trussell, et al., 2013). 
A relatively high proportion of unintended pregnancies and its health and economic consequences show a need to estimate economic burden of unintended pregnancies in local context of Nepal which can be instrumental in public health policy debates. The evidence can help policy makers decide which conditions need to be addressed first by health care and prevention policy, associated potential savings from eliminating the condition and fiscal space improvement (Byford, et al, 2000). However, till date there is no information about how much cost do the unintended pregnancies incur to the society in Nepal. This study, therefore, aims to estimate national economic burden of unintended pregnancies adopting societal perspective. In order to meet this objective, first, we estimated direct and indirect cost of pregnancy outcomes which were combined with national prevalence and consequences of unintended pregnancies to reach an estimate of the total economic burden. In the next section, estimation methodology, approach and modeling techniques are described.

\section{METHODOLOGY}

The economic burden covers total resources forgone by the society to manage a series of pregnancy outcomes between conception and post-natal period resulting from

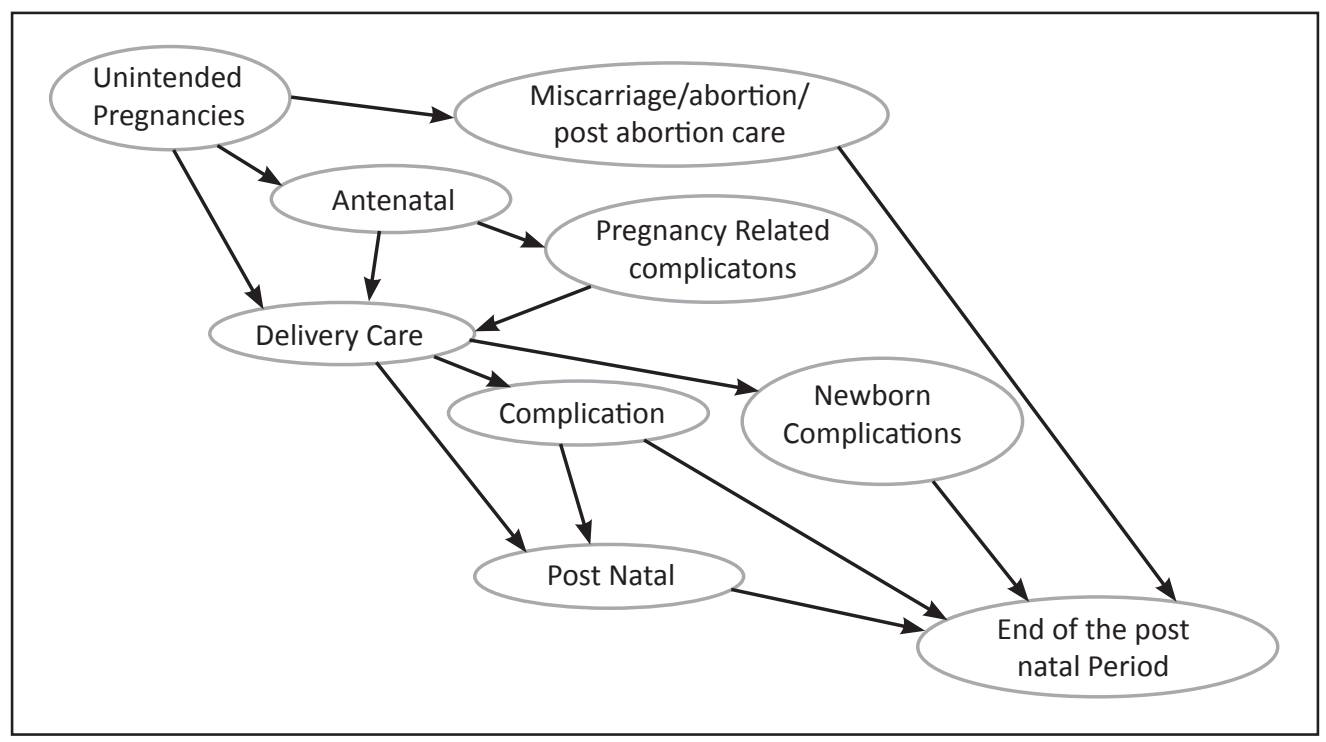

Figure 1: Summary of Markov Model

unintended pregnancies. In order to meet the objective, an appropriate life course modelling technique is needed to connect pregnancy outcomes between conception 
and post-natal period. Markov model has been considered useful for such purpose in the literature(Briggs \& Sculpher, 1998). In this study, we, therefore, adapted Markov modeling technique to estimate the economic burden. In the section below, we have described a fairly detail methodology associated with the modelling technique, information requirements of the model and sources of information.

\section{Model}

A Markov model was adopted to estimate the burden of unintended pregnancies at national level because of its ability to model events occurring over the period of time in a well-connected manner. Basic structure of the model is shown in figure 1. It includes pregnancy outcomes that can occur between the conception and post-natal period. These pregnancy outcomes are represented in Figure 1 using oval structures also called Markov states. The model has an initial stage from where all the sequences of pregnancy outcomes start. A national cohort of unintended pregnancies forms the initial stage for this model. The women undergo different stages of pregnancy according to the transition probabilities represented by arrows in the figure 1. Transition probabilities are the epidemiological parameters which show the proportion of pregnancies undergoing different stages outlined in Table 1. The pregnancy outcomes are non-recurrent in nature which means that once the women have moved to next stage; it is not possible to revert back to the initial stage. The 'Post-natal care' state is an absorbing state since women who transit to this state complete the hypothesized time period for our study. This model has information requirements in terms of transition probabilities and Markov states. Transition probabilities were collected from various secondary sources. Table 3 shows the probabilities along with the source of information. Markov states represent the total cost forgone by the society to manage a case of pregnancy outcome outlined

in Table 1. In the next section, theoretical and methodological approach for costing pregnancy outcomes is described.

\section{Costing Pregnancy Outcomes}

In our study, we outlined various consequences of unintended pregnancies that are policy relevant. For this purpose, we reviewed national guidelines and plans $(24,25)$ and came-up with services and conditions outlined in Table 1 called Markov states. These states form specific conditions of unintended pregnancies that need unit cost. 
Table 1 : Various Pregnancy Outcomes for an Unintended Pregnancy Considered in This Study

\begin{tabular}{ll}
\hline Stages & Pregnancy Outcomes \\
\hline Termination of & $\begin{array}{l}\text { Spontaneous abortion, induced abortion (instrumental and } \\
\text { medical abortion) and Post-Abortion Care (PAC) }\end{array}$ \\
Antenatal Period & $\begin{array}{l}\text { Antenatal care and complication management (Pre/Eclampsia, } \\
\text { Fits management, Jaundice, Severe Hyperemesis gravidarum, } \\
\text { Antepartum Hemorrhage, Urinary Tract Infections (UTI)/ } \\
\text { Pyelonephritis, Premature rupture of membrane) }\end{array}$ \\
Intra-natal Period & $\begin{array}{l}\text { Delivery (Normal, Instrumental, Cesarean Section (CS)), } \\
\text { complications during this period(post-partum cardiomyopathy, } \\
\text { deep vein thrombosis, retained placenta, post-partum } \\
\text { psychosis, mastitis management, post-partum hemorrhage, } \\
\text { post-partum sepsis etc.), } \\
\text { Newborn care and complications management in indoor } \\
\text { including Neonatal Intensive Care Unit (NICU). }\end{array}$ \\
Post-natal period & $\begin{array}{l}\text { Post-natal care and check-up, newborn care, management of } \\
\text { newborn complications up to 45 days of birth. }\end{array}$ \\
\hline
\end{tabular}

In the second stage, we adapted societal perspective to identify the types of cost that will be covered in the unit cost. The cost categories covered are namely direct medical cost which covered consultation fees, hospital charges for case management, medicines and accessories for procedures and Investigations; direct non-medical cost covered transportation to health facilities and cost of lodging and food while receiving services; Indirect cost covered informal care time by the friends and family members, and productivity loss of the client and patient while receiving services. Similarly, we adapted prevalence based Cost of Illness (COI) approach for this study. The retrospective approach was adapted to collect the data on use of above mentioned resources.

In the third stage, measurement of resources was performed. Resources use for direct medical cost was based on hospital records of use of services and prices for consultations, bed charges, medicine, investigations etc. Patients were interviewed for the direct non-medical costs and indirect costs. We used standard productivity cost questionnaire developed by Bouwmans, et al. (2013) and patient and family care takers' time cost questionnaire developed by Hoefman, et al.(2013). In this stage, we adapted a mix of micro and gross costing approach. 
In fourth stage, valuation of resources was accomplished. It was performed using bottom-up approach where resources need to be multiplied by unit prices (Drummond \& McGuire, 2001; Drummond, et al., 2007; Tan, et al., 2009). Direct and indirect costs were valued to assess the total economic COI. Hospitals where charges were not available, for example public/community hospitals and private hospitals implementing maternity incentive scheme, a universal demand side financing mechanism by Government of Nepal (GoN), hospital service charges were obtained from nation-wide costing study (Ensor, et al., 2015). Indirect costs were valued using human capital approach. Time forgone by the patients and care-givers were valued using minimum wage rate suggested by the GoN (Government of Nepal, 2012). All the costs incurred within a year's time which precludes the necessity of discounting.

\section{Data Sources, Management and Analysis}

Thirty hospitals were selected purposively within Kathmandu valley. Hospitals were selected such that the sample covers public, community and private hospital, medical college and international level private hospitals in Nepal. We got approval for data collection only from 27 out of 30 hospitals approached. Data for direct medical cost of various pregnancy outcomes were collected from these hospitals. Direct non-medical and indirect costs were collected from a sample of 121 mothers receiving maternity services from 27 hospitals. Women visiting selected hospitals for the maternal services were interviewed to collect non-medical and indirect costs. Questionnaires were carefully designed with reference to the national medical standards for reproductive health (Government of Nepal, Ministry of Health and Population, \& Family Health Division, 2007) and skilled birth attendant guideline (National Health Training Center, 2008) of Nepal. In order to measure the resources lost for productivity loss and informal care givers time, standard questionnaires (Bouwmans, et al., 2013; Hoefman,et al., 2013) were adapted.

All the cost data from hospitals were entered and analyzed in MS Excel. Direct nonmedical and indirect costs were entered in SPSS (Bühl, 2012)and analyzed in R (R Core Team, 2014). Unit costs for each pregnancy outcomes were calculated. The Markov model outlined in figure 1 was developed in TreeAge Pro (2011). Model parameters in terms of cost and proportions for Markov states and state transition probabilities entered in the model accordingly as shown in table 2 and 3. Altogether a cohort of 186284 (Department of Health Services, 2014) unintended pregnancies were entered in the model. In this manner, total burden associated with the unintended pregnancies was estimated.

Univariate sensitivity analysis was performed to observe how sensitive the estimated annual burden towards the variation in cost of each component outlined in Table 2 . 
Ethical aspects were maintained at every stage of the research process. Ethical clearance was taken from Nepal Health Research Council (NHRC). Then, informed consent was ensured from hospitals and mothers while collecting data.

Table 2: Total Cost to Manage the Pregnancy Outcomes (in US \$ )

\begin{tabular}{llll}
\hline SN & Outcomes & \multicolumn{2}{c}{ Unit Cost } \\
\cline { 3 - 4 } & & $\begin{array}{l}\text { Provider } \\
\text { Perspective }^{4}\end{array}$ & Societal \\
Perspective $^{5}$ \\
\hline 1 & Antenatal Care & 2731.28 & 4003.95 \\
2 & Instrumental Abortion & 3120.04 & 7294.45 \\
3 & Medical abortion & 2066.41 & 2384.55 \\
4 & Post abortion care & 6307.89 & 18795.67 \\
5 & Pre-eclampsia & 4465.15 & 41608.73 \\
6 & Fits management & 3751.27 & 40894.85 \\
7 & Jaundice & 4852.18 & 41995.77 \\
8 & Severe hyperemesis gravidrum & 4372.61 & 41516.19 \\
9 & Antepartum Haemorrhage & 6092.50 & 43236.09 \\
10 & UTI/Pyelonephritis & 4069.09 & 41212.67 \\
11 & Membrane Rupture & 3845.20 & 40988.79 \\
12 & Normal Delivery & 9532.08 & 18500.75 \\
13 & Instrumental delivery & 9639.99 & 18608.66 \\
14 & Vacuum delivery & 9491.88 & 18460.44 \\
15 & Cesarean section & 23287.05 & 35895.42 \\
16 & Post-natal care & 419.17 & 1373.70 \\
17 & Post-partum Haemorrhage & 5774.47 & 42918.05 \\
18 & Post-partum sepsis & 15519.36 & 52662.94 \\
19 & Mastitis management & 10108.49 & 47252.08 \\
20 & Post-partum psychosis & 770.20 & 37913.78 \\
21 & Retained Placenta & 6239.75 & 43383.33 \\
22 & Deep vein thrombosis & 9716.62 & 46860.21 \\
23 & Post-partum cardiomyopathy & 15832.02 & 52975.60 \\
24 & Neonatal Intensive Care Unit (NICU) & 2622.08 & 17377.58 \\
25 & Incubator & 1784.49 & 16539.88 \\
\hline & & & \\
\end{tabular}

4 Direct Medical Costs

5 Direct medical costs, direct non-medical costs, indirect costs (productivity loss and informal care giving) 


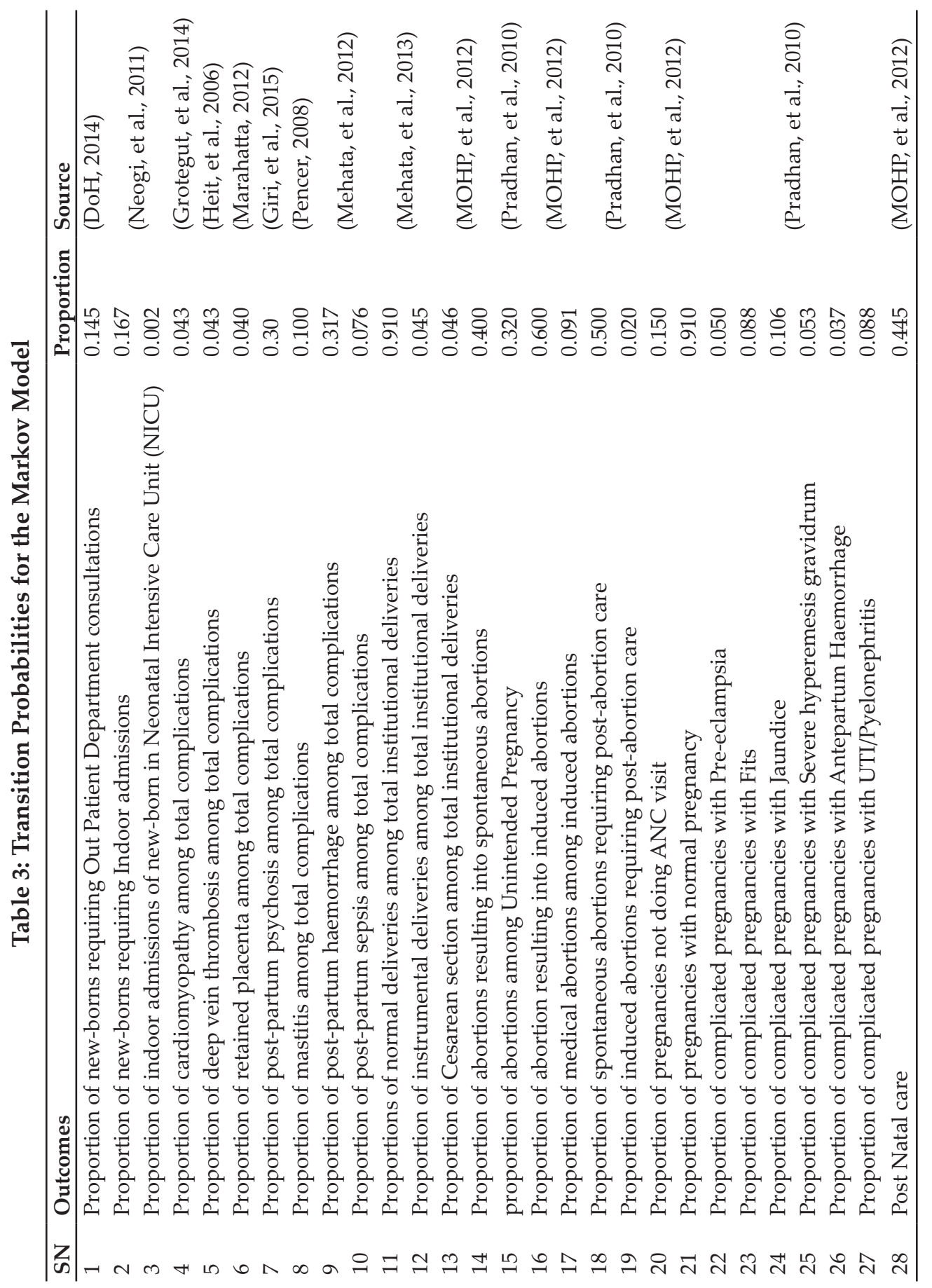




\section{FINDINGS}

In this section results from Markov model that incorporates total burden of unintended pregnancies in terms of different consequences and their monitory value including sensitivity analysis.

\section{National Annual burden of unintended pregnancies}

Table 4 shows the estimates of total annual burden of unintended pregnancies from provider and societal perspective. Annual expected cases of unintended pregnancies were 186,284(DoHS, 2012). Total annual burden from societal perspective equals to 12330.59 million NPR. However, from provider perspective, it is 2649.59 million NPR. The share of total annual burden differed between the perspectives. From the provider perspective, the greatest share is accounted by the delivery services $(63.19 \%)$, followed by complications management during pregnancy and delivery (11.67\%). Altogether, abortion services and post-abortion care account only for 8.09 percent of total costs.

ANC services take account of 11.23 percentage of total burden from provider perspective. The share of delivery services which accounted for the highest share of annual burden dropped from 63.19 percent to 24.84 percent in societal perspective. Post-natal care and check-ups accounted for the the greatest share $(40.42 \%)$ of total burden which was nominal in case of provider perspective. ANC check-ups accounted for $3.54 \%$ share of total burden. Complications management during pregnancy and delivery accounted for 20.14 percent.

Table 4: National annual burden of unintended pregnancies from provider and societal perspectives (in million NPR dollars)

\begin{tabular}{|c|c|c|c|c|}
\hline \multirow{2}{*}{ Pregnancy Outcomes } & \multicolumn{2}{|c|}{ Provider Perspective } & \multicolumn{2}{|c|}{ Societal Perspective } \\
\hline & Total cost & $\%$ annual costs & Total cost & $\%$ annual costs \\
\hline Total Abortion/PAC cost & 214.8 & 8.09 & 539.148 & 4.37 \\
\hline ANC check-up & 297.498 & 11.23 & 436.044 & 3.54 \\
\hline $\begin{array}{l}\text { Complication management } \\
\text { during pregnancy and } \\
\text { delivery }\end{array}$ & 309.312 & 11.67 & 2483.088 & 20.14 \\
\hline Delivery services & 1674.366 & 63.19 & 3061.974 & 24.84 \\
\hline $\begin{array}{l}\text { Complication management- } \\
\text { newborn }\end{array}$ & 119.214 & 4.52 & 825.906 & 6.7 \\
\hline PNC visit and $\mathrm{HH}$ care & 34.368 & 1.3 & 4983.36 & 40.42 \\
\hline TOTAL & 2649.558 & 100 & 12330.59 & 100 \\
\hline
\end{tabular}

Figure 3 shows sensitivity analysis of the total burden. The univariate sensitivity analysis is performed using bootstrap method with 1000 replications. Sensitivity of 
the total figure for each pregnancy outcome is shown in figure in terms of width of the error bar. The total annual burden is most sensitive to the cost of normal delivery. Next most influencing state is CS delivery. Third most influencing pregnancy state is ANC services. Complications during pregnancy and delivery account of small variation in total burden. The sensitive range of burden is shown in the figure 3 .

\section{DISCUSSION AND CONCLUSION}

Our analysis estimates cost per unintended pregnancy from provider and societal perspective to be 2649.56 and 12330.59 NPR respectively. This estimate factors in a range of health related costs attributed to abortions, regular ANC visits, delivery care, and complication management during pregnancy, delivery and new-borns. These health consequences were costed using COI approach. The greatest share of the burden from provider perspective was borne by delivery services (63\%) followed by complications management $(11.67 \%)$. However, from societal perspective, the picture is slightly different, postnatal care accounts for a huge share $(46.4 \%)$ of the total burden, and the share of delivery services reduces to 28.51 percent.

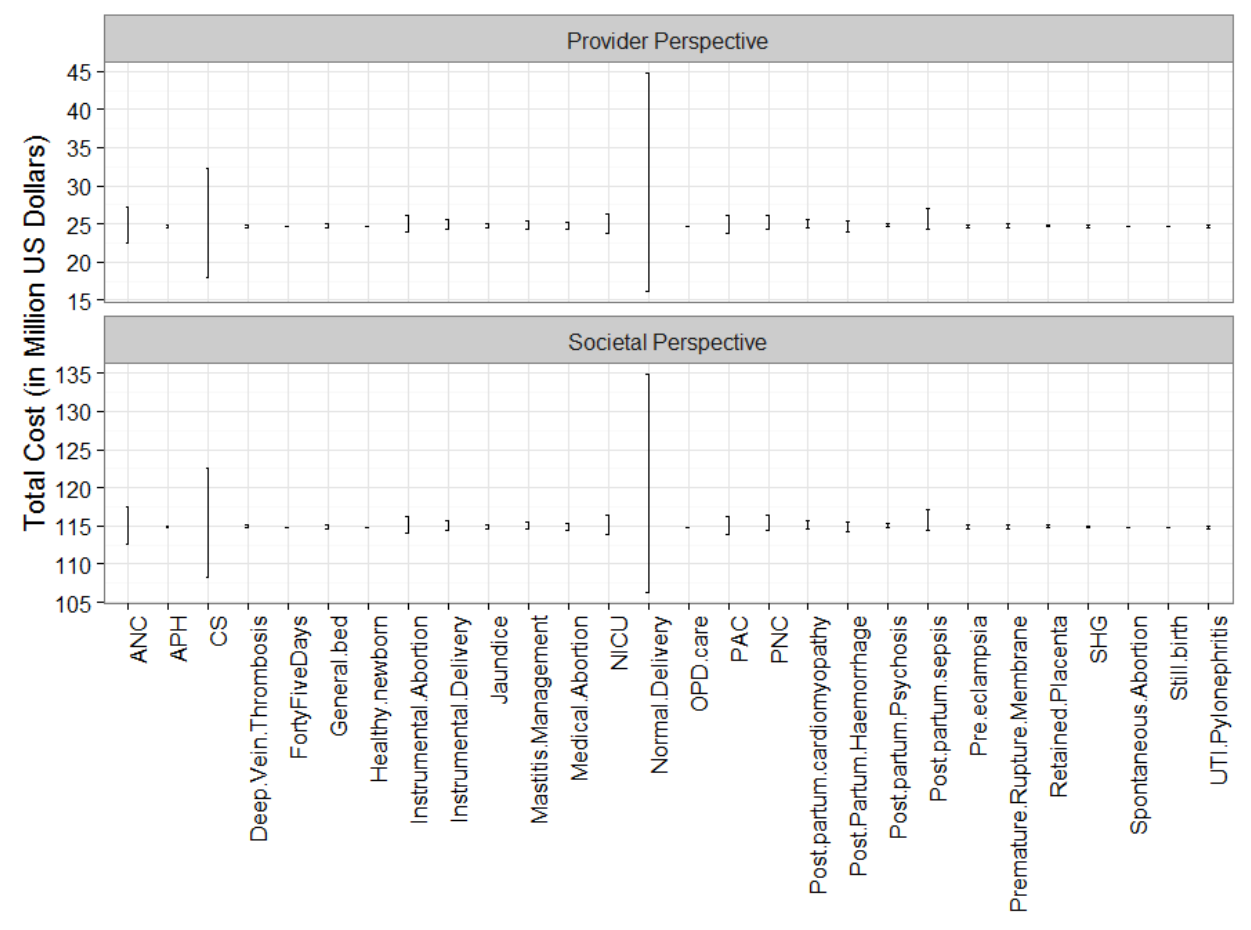

State

Figure 3: Sensitivity Analysis of Total Annual Economic Burden from Provider and Societal Perspective 
Our estimates of unit cost are broadly similar to those estimated by others. Most of the studies only measured direct medical costs. Studies in Bolivia, Mexico, and Peru showed that the cost per patient for inpatient dilatation and curettage services ranged from \$66-151 (Grimes, et al., 2006). Similarly, cost of post abortion care was estimated to be $\$ 83$ in Africa and $\$ 94$ in Latin America (Vlassoff, M., Walker, D.,et al., 2009). Cost of providing delivery services was $\$ 63$ US in Ghana which varies in a range of $\$ 12$ and $\$ 152$ among the health centers (Dalaba, et al., 2013). Previous study by Gibbons, et al. (2010) reported the estimated cost of providing delivery services to be $\$ 97$ in Nepal. Same study showed that in India and Bangladesh, the figure is nearly same i.e. \$105 and $\$ 98$ respectively. Hoque, et al., (2012) estimated the average cost of managing maternal complications to be varying from $\$ 9$ to $\$ 251$. The estimated burden is most sensitive to the unit cost for normal delivery, CS and ANC services. This is due to the fact that there is the greatest variation in the unit cost at government and private institutions.

Our estimates of unit cost and total economic burden are not without limitations. For direct medical cost, we sampled hospitals only from Kathmandu valley. This certainly raises the question over representativeness. In order to deal with this issue, we covered wide variety of hospitals such as Public hospitals, community hospitals, teaching hospitals, private hospitals and clinics, and international hospitals) in our sample. Similarly, we considered hospital price for various services as the marginal cost in order to reach the estimate of unit cost for the services. However, this assumption is expected to inflate the unit cost as hospital care markets are not monopolistic and several market distortions exist. In such circumstances, it is likely that marginal cost of service will be quite below the market price which leads to higher estimated unit cost from provider perspective. This aspect should be taken care of while interpreting the results. Similarly, we could not cover intangible cost related to pain and suffering in unit cost. While estimating annual economic burden using Markov model, many of the transition probabilities (Table 3) were actually based on total pregnancies rather than unintended pregnancies. This is due to the fact that it was not possible to tract the unintended pregnancies at national level. In this connection, the Puri, (2006)also states that the unintended pregnancies are likely to undergo adverse consequences compared to normal pregnancies. This can lead to underestimated numerical estimates. Similarly, transition probabilities for maternal and newborn complications were not available in national context. So, we considered estimates from international scenarios. This is likely to bias the actual figure. However, the proportion of complications in mother and newborn is quite low which is expected narrow down the biasness. The time period in our analysis is between the beginning of pregnancy and post-partum period. This precludes the future cost of various consequences after post-partum period. This is another study limitation worth considering while interpreting the 
results. Again, we could not cover the cost associated with loss of life such as maternal and newborn deaths as the consequences of unintended pregnancies. Other literatures however included such consequences in their cost estimates.

Above discussion sheds light on the fact that there are a few stringent assumptions and limitations that can bias the total economic burden in either direction. However, keeping the limitations in mind, current estimates are first of its kind in context of Nepal and can be useful to policy makers in several ways. First of all, caesarian section delivery has comparatively high direct medical cost which is provided free of cost from public institutions. Similarly, proportions of caesarian section delivery are increasing every year (DOH, 2014), which indicates that unintended pregnancies proportionately use CS deliveries indicating increasing burden on providers. On the other hand, the complications during pregnancy delivery and post-partum period has proportionately higher share of indirect and direct non-medical cost which means greater burden on clients and families. The economic burden of unintended pregnancies shows the monitory equivalent which is avoidable and can be employed in several ways. Share of economic burden is more than 70 percent for consumers (patients) which shows that the greatest burden of such pregnancies falls on consumers. Such a huge burden is suggests policy makers to initiate strategic initiatives to prevent unintended pregnancies. The results also pertinent to the policy makers when the national is struggling to improve the fiscal space of the current ongoing programs in a sustainable manner. So, minimizing unintended pregnancies will provide enough fiscal space to improve allocation in this program. Similarly, other programs also can be benefitted with creating fiscal space by avoiding unintended pregnancies. Such fiscal space will also ensure fiscal sustainability, a policy goal of ministry of health and population (GON, 2010). The ministry, therefore, will be benefitted from the efficiency gains resulting from avoiding unintended pregnancies that has huge annual economic burden.

The above analysis shows that despite the study limitations, the unit cost of unintended pregnancy outcomes and total economic burden are useful for policy makers and planners in Nepal. The figure indicates country can benefit from preventing unintended pregnancies in particularly fiscal space gains and decrease is economic burden that goes to consumers. The analysis also provides information about where the burden of unintended pregnancies is going to fall so that policy makers can take early measures to decrease the future burden on the services. The discussion also sheds light on the efficiency gains by avoiding UP which provides a room for improving fiscal space gradually in future in sustainable manner. The study also concludes that more research is needed to cover the economic burden of beyond post-partum period that can be attributable to unintended pregnancy. 


\section{Declaration Section}

\section{List of Abbreviations}

COI Cost of Illness

GoN Government of Nepal

NHRC Nepal Health Research Council

ANC Ante-natal Care

PNC Post Natal Care

PAC Post Abortion Care

USD United States Dollars

CS Caesarian Section

\section{Ethics}

The study was conducted considering all the ethical principles underlying the research. Ethical approval was taken from Ethical Committee at Nepal Health Research Council (NHRC).

\section{Consent to participate}

Informedconsentwastakenfromhospitalsand pregnantwomenbeforecollectingthedata. Acknowledgement: We would like to acknowledge GIZ-Health Sector Support Program for providing funds and Institute for Nepal Environment and Health System Development (INEHD) for regular support. We are grateful to Mr. Ghanashyam Pokharel, Family Health Division, Department of Health Services (DoHS) for his suggestions and support during this study. We are also thankful to Mr. Santosh Kumar Shah and Ms. Sabita Acharya for their support during the study. At last but not least, we are grateful to hospitals and all the mothers who provided information for this study.

\section{References}

Bouwmans, C., Roijen,L.H.-van, Koopmanschap, M., Krol, M., Severens, H., \& Brouwer, W. (2013). iMTA productivity costs questionnaire.

Briggs, A., \& Sculpher, M.(1998). An introduction to markov modeling for economic evaluation. Pharmacoeconomics, 13, 397-409.

Bühl, von-A. (2012). SPSS 20: Einführung in die moderne Datenanalyse: Pearson.

Byford, S., Torgerson, D., \& Raftery, J. (2000). Economic note-cost of illness studies. British Medical Journal, 320(7245), 1335. 
Dalaba, M.A., Akweongo, P., Savadogo, G., Saronga, H., Williams, J., Sauerborn, R., . . L Loukanova, S. (2013). Cost of maternal health services in selected primary care centres in Ghana: A step down allocation approach. BMC Health Services Research, 13(1), 287.

Department of Health Services (DoHS) (2014). Annual report. Kathmandu: Department of Health Services, Ministry of Health and Population Nepal. Services.

. (2014). Annual health report-2012/13. Kathmandu: Department of Health

\begin{abstract}
Services.
\end{abstract}
DoHS. (2011/12). Annual report.Kathmandu: Government of Nepal.

Drummond, M.F., \& McGuire, A.(Eds.). (2001). Economic evaluation in health care: Merging theory with practice. Oxford: Oxford University Press.

Drummond, M.F., Torrance, G.W., Sculpher, M.J., O’Brien, B., \& Stoddart, G.L. (2007). Methods for the economic evaluation of health care programmes.Oxford: Oxford University Press.

Ensor, T., Bhatta, H., \& Suvedi, B.K. (2015). Preliminaries findings from unit cost analysis of the health facility reimbursement made under the Aama program. Kathmandu Nepal.

Gibbons, L., Belizán, J.M., Lauer, J.A., Betrán, A.P., Merialdi, M., \& Althabe, F. (2010). The global numbers and costs of additionally needed and unnecessary caesarean sections performed per year: Overuse as a barrier to universal coverage (World Health Report 2010 , Background Paper No. 30). World Health Organization.

Giri, R.K., Khatri, R.B., Mishra, S.R., Khanal, V., Sharma, V.D., \& Gartoula, R.P. (2015). Prevalence and factors associated with depressive symptoms among postpartum mothers in Nepal. BMC Research Notes, 8(1), 111.doi:10.1186/s13104015-1074-3

Government of Nepal. (2010). Nepal health sector programme-2, Implementation plan 20102015. Ministry of Health and Population . (2012). Nepal Gazette: New minimum wage rate. Kathamndu.

Government of Nepal, Ministry of Health and Population, and Family Health Division. (2007). National medical standard for reproductive health, volume III. Kathmandu: Family Health Division.

Grimes, D.A., Benson, J., Singh, S., Romero, M., Ganatra, B., Okonofua, F. E., \& Shah, I.H. (2006). Unsafe abortion: The preventable pandemic. The Lancet, 368(9550), 1908-1919. 
Grotegut, C.A., Kuklina, E.V., Anstrom, K.J., Heine, R.P., Callaghan, W.M., Myers, E.R., \& James, A.H. (2014). Factors associated with the change in prevalence of cardiomyopathy at delivery in the period 2000-2009: A population-based prevalence study. BJOG: An International Journal of Obstetrics \& Gynaecology, 121(11), 1386-1394.

Heit, J.A., Kobbervig, C.E., James, A.H., Petterson, T.M., Bailey, K.R., \& Melton III,L.J. (2006). Trends in the incidence of venous thromboembolism during pregnancy or postpartum: A 30-year population-based study. Obstetrical \& Gynecological Survey, 61(4), 220-221.

Henry, N., Schlueter, M., Lowin, J., Lekander, I., Filonenko, A., Trussell, J., \& Skjeldestad, F. E. (2015). Cost of unintended pregnancy in Norway: A role for long-acting reversible contraception. Journal of Family Planning and Reproductive Health Care, 41, 109-115. doi: http://dx.doi.org/10.1136/jfprhc-2014-100878

Hoefman, R.J., Van Exel, N.J.A., \& Brouwer, W.B.F. (2013). iMTA valuation of informal care questionnaire MANUAL.

Hoque, M.E., Powell-Jackson, T., Dasgupta, S.K., Chowdhury, M. E., \& Koblinsky, M. (2012). Costs of maternal health-related complications in Bangladesh. Journal of Health, Population, and Nutrition, 30(2), 205-212.

Jessica D. G., Michael A. K., \& Hindin, M. J. (2008). The effects of unintended pregnancy on infant, child and parental health: A review of the literature. Studies in Family Planning, 39(1), 18-38.

John S., Roger R., Kendra H.-T., Brenda C. G., Kathryn C., Rebecca C., . . Schieve, L.. (2003). The measurement and meaning of Unintended Pregnancy. Perspectives on Sexual and Reproductive Health, 35(2), 94-101.

Kubička, L, Matějček, Z, David, HP, Dytrych, Z, Miller, WB, \& Roth, Z. (1995). Children from unwanted pregnancies in Prague, Czech Republic revisited at age thirty. Acta Psychiatrica Scandinavica, 91(6), 361-369.

Le, H.H, Connolly, M. P., Bahamondes, L., Cecatti, J. G., Yu, J., \& Hu, H.X. (2014). The burden of unintended pregnancies in Brazil: a social and public health system cost analysis. International Journal of Women's Health, 20(4-6), 663-670.

Lete, I., Hassan, F., Chatzitheofilou, I., Wood, E., Mendivil, J., Lambrelli, D., \& Filonenko, A.. (2015). Direct costs of unintended pregnancy in Spain. The European Journal of Contraception and Reproductive Health Care(0), 1-11.

Marahatta, R. (2012). Retained placenta--a major cause of maternal morbidity. Nepal Medical College journal: NMCJ, 14(1), 41-45. 
Mehata, S., Baral, S. C., Chand, P. B., Singh, D. R., Poudel, P., \& barnett, S.. (2012). Nepal household survey 2012. Kathmandu, Nepal: Ministry of Health and Population, Government of Nepal.

Mehata, S., Lekhak, S. C., Chand, P. B., Singh, D. R., Poudel, P., \& Barnett, S.. (2013). Service tracking survey 2012. Kathmandu: Ministry of Health and Population, Government of Nepal.

Ministry of Health and Population (MOHP) [Nepal], New ERA, \& Macro International Inc. (2012). Nepal demographic health survey 2011. Kathmandu.

National Health Training Center. (2008). Skilled Birth Attendant (SBA) In-service training course reference manual in Nepali from IMPAC. Kathmandu: Natinal Health Training Center, Ministry of Health and Population.

Neogi, S. B., Malhotra, S., Zodpey, S., \& Mohan, P.. (2011). Assessment of special care newborn units in India. Journal of Health, Population, and Nutrition, 29(5), 500.

Pradhan, A., Suvedi, B. K., Barnett, S., Sharma, S. K., Puri, M., Poudel, P., ... Hulton, L.. (2010). Nepal maternal mortality and morbidity study2008/2009. Kathmandu.

Pulley, L.V., Klerman, L V, Tang, H., \& Baker, B. A. (2002). The extent of pregnancy mistiming and its association with maternal characteristics and behaviors and pregnancy outcomes. Perspectives on Sexual and Reproductive Health, 206-211.

Puri, M.. (2006). Consequences of unintended pregnancy among young married women in Nepal. N. J. Ostet Gynaecol, 1(2), 37-46.

Pencer, S., \& Jeanne, P. (2008). Management of mastitis in breastfeeding women. Am Fam Physician, 78(6), 727-731.

R Core Team. (2014). R: A language and environment for statistical computing. . Retrieved from http://www.R-project.org/.

Singh, A., Chalasani, S., Koenig, M. A., \& Mahapatra, B. (2012). The consequences of unintended births for maternal and child health in India. Population Studies, 66(3), 223-239.

Singh, A., Singh, A. \& Thapa, S. (2013). Adverse consequences of unintended pregnancy for maternal and child health in Nepal. Asia Pacific Journal of Public Health (online). doi: 10.1177/1010539513498769

Sonfield, A., Kost,K., Gold,R.B., \& Finer, L. B. (2011). The public costs of births resulting from unintended pregnancies: national and state-level estimates Perspectives on Sexual and Reproductive Health, 43(2), 94-102. doi: 10.1363/4309411 
Tan, S. S., Rutten, F.F.H., Van I., Redekop, W.K., \& Hakkaart-van R., L. (2009). Comparing methodologies for the cost estimation of hospital services. The European Journal of Health Economics, 10(1), 39-45.

TreeAge Pro. (2011). TreeAge Software Inc: Williamstown.

Trussell, J., Henry, N., Hassan, F., Prezioso, A., Law, A., \& Filonenko, A. (2013). Burden of unintended pregnancy in the United States: Potential savings with increased use of long-acting reversible contraception. Contraception, 87(2), 154-161.

Vlassoff, M., Walker, D., Shearer, J., Newlands, D., \& Singh, S.. (2009). Estimates of health care system costs of unsafe abortion in Africa and Latin America. International Perspectives on Sexual and Reproductive Health, 114-121. 